\title{
PEMANFAATAN INTERNET SEHAT MENUJU GENERASI UNGGUL DI ERA MILENIAL
}

\section{The Utilization Of Healthy Internet Towards Superior Generations In The Millenial Era}

\author{
Adji Suradji Muhammad ${ }^{*}$, Imam Yudhi Prastya ${ }^{2}$ \\ 1) 2) Program Studi Ilmu Administrasi Negara, Fakultas Ilmu Sosial dan Ilmu Politik, \\ Universitas Maritim Raja Ali Haji, Tanjungpinang \\ *Korespondensi : suradji@umrah.ac.id
}

\begin{abstract}
ABSTRAK
Perkembangan informasi dan komunikasi melalui teknologi saat ini begitu cepat, sehingga tidak mengenal batas wilayah dan batas privasi. Perkembangan teknologi tersebut juga memicu hadirnya media baru yang dikenal dengan Media Sosial. Media sosial pada umumnya adalah media yang digunakan untuk bersosialisasi atau berhubungan, baik secara personal maupun impersonal antar penggunanya. Beberapa aplikasi media sosial yang ada saat ini antara lain adalah WhatsApp, Facebook, Twiter, Blackberry Massager, Path, Skype, Instagram SNS dan Communication Network. Secara garis besar media sosial dan jaringan sosial menggunakan sistem yang sama yaitu media daring yang terhubung dengan internet. Pada media sosial dan jaringan sosial, ada banyak orang yang saling terhubung satu sama lain tanpa dibatasi dengan batas fisik seperti geografis, ruang, bahkan waktu dengan tujuan untuk saling berkomunikasi, berbagi sesuatu, berpendapat, menjalin komunikasi yang lebih intens. Sehingga banyak mengakibatkan timbulnya hubungan yang tidak sesuai dengan norma dan etika ditengah-tengah masyarakat. Tujuan diadakannya kegiatan literasi media adalah dalam rangka melindungi masyarakat (terutama pelajar) dari pengaruh negatif media sosial serta menciptakan audiens yang kritis. Kegiatan ini merupakan hal baru yang signifikansi dan daya Tarik tersendiri sehingga perlu dilakukan sosialisasi. Kegiatan tentang literasi media sosial dalam tataran konkret dilaksanakan dengan metode turun kelapangan yaitu mengunjungi sekolah. Tiga aspek dasar program literasi yaitu: Pertama, pembentukan aspek kognitif dalam pengetahuan menggunakan media sosial di kehidupan sehari-hari. Kedua, pembentukan aspek afektif dalam pembentukan pribadi yang bertanggungjawab sebagai generasi penerus bangsa. Ketiga, pembentukan aspek psikomotorik (keterampilan siswa) yang menjadikan siswa tanggap dan kreatif dan cerdas dalam menggunakan media sosial.
\end{abstract}

Kata Kunci: Internet Sehat, Literasi, Pelajar.

\section{ABSTRACT}

The development of information and communication through technology today is so fast so that they do not recognize territorial borders and privacy boundaries, These technological developments also triggered the emergence of new media, known as Social Media. Social media in general are media that are used to socialize or connect, both personally and impersonal between users. Several social media applications that exist today These include WhatsApp, Facebook, Twitter, Blackberry Massager, Path, Skype, SNS Instagram, and Communication Network. Broadly speaking social media and social networks use the same system that is online media connected to the internet. On social media and social networks, many people are connected without being bound by physical boundaries such as geography, space, even time to 
communicate with each other, share something, argue, establish more intense communication. So much resulting in the emergence of relationships that are not by the norms and ethics amid society. The purpose of holding media literacy activities is to protect the public (especially students) from the negative influence of social media and creates a critical audience. This activity is a new thing that has its significance and attraction so it needs to be done with socialization. Activities on social media literacy at a concrete level are carried out using the field drop method, namely visiting the school. Three basic aspects of the literacy program such as First, the formation of cognitive aspects in knowledge using social media in everyday life. Second, the formation of affective aspects in the formation of a responsible person as the next generation of the nation. Third, the formation of psychomotor aspects (student skills) which makes students responsive and creative and smart in using social media.

Keywords: Healthy Internet, Literacy, Students.

\section{PENDAHULUAN}

Masyarakat sangat berharap bahwa Perguruan Tinggi dapat ikut serta dan berkiprah dalam memecahkan berbagai permasalahan bangsa yang ada. Dalam rangka mengemban dan melaksanakan amanah "Tri Darma Perguruan Tinggi", pengabdian pada masyarakat merupakan tuntutan yang wajib di laksanakan. Hal ini sekaligus sebagai bukti bahwa Perguruan Tinggi ikut serta dalam mencerdaskan kehidupan berbangsa yang berlandaskan pada pengembangan Teknologi Informasi.

Memasuki era millennium saat ini, dunia terasa flat/datar. Hal ini disebabkan arus informasi dan komunikasi tidak lagi menjadi penghalang. Apa yang terjadi dibelahan dunia, pada saat yang bersamaan dapat pula kita saksikan. Dengan demikian tidak ada lagi batasan antara satu daerah dengan daerah lainya, antara satu Negara dengan Negara lainya. Salah satu adalah munculnya teknologi internet yang saat ini telah memberikan banyak manfaat bagi kehidupan, bahkan mampu merubah peradaban manusia. Internet akhirnya menjadi sesuatu yang sangat penting untuk dipelajari dan dikuasai oleh setiap orang. Bahkan untuk lebih mempermudah lagi, diciptakan berbagai jenis gadget dengan segala macam perangkat canggihnya. Hingga "dunia" bisa kita genggam di tangan, dan ditenteng kemana-mana.

Teknologi informasi adalah kunci dalam menyebarluaskan informasi sehingga bagi sebagian orang penguasaan teknologi informasi menjadi sebuah keniscayaan untuk dapat menguasai dunia. Hanya saja kemajuan tekhnologi terkadang memberikan efek samping yang tak mampu kita hindari. Ketidaksiapan masyarakat kita untuk menerima perkembangan teknologi yang membawa dunia pada serba internet ini tidak hanya berkontribusi menyumbangkan pengaruh positif namun juga negatif. Penggunaan internet termasuk dididalamnya jejaring social oleh pelajar dan mahasiswa dapat memberikan efek buruk baik untuk perkembangan social, psikologis maupun akademiknya. (Hidayanto \& Zidni Ilmi, 2015), (Rosyidah, 2016)

Maraknya pemberitaan ditelevisi maupun dimedia-media lainya terkait dengan banyaknya penyimpangan dalam menggunakan internet baik dilakukan oleh masyarakat umum maupun pelajar, membuat banyak kalangan merasa prihatin. Ironisnya akhir-akhir ini, pelajar ditingkat sekolah dasar sudah sangat bebas berinteraksi dengan teknologi dan internet. Hal ini menimbulkan banyaknya pelajar yang memiliki perilaku menyimpang. Willis (2005) menyatakan bahwa kenakalan remaja diartikan sebagai suatu hasil dari proses yang menunjukkan penyimpangan tingkah laku atau pelanggaran terhadap norma yang ada (Asniati.et.all., 2020). Seperti halnya Jika anak terlalu banyak berkomunikasi di dunia maya, maka pengetahuan tentang seluk beluk 
berkomunikasi di kehidupan nyata, seperti bahasa tubuh dan nada suara, menjadi berkurang (Anggreini, Nasir, \& Noor, 2016). Peran pemerintah dalam upaya membentengi pelajar dari perilaku menyimpang sangatlah diperlukan. Sayangnya peran tersebut belum bisa maksimal dilakukan oleh pemerintah dengan berbagai alasan diantaranya alasan anggaran dan sumberdaya manusia.

Pesatnya perkembangan teknologi informasi yang berbasis computer atau yang biasa kita kenal dengan istilah internet. Internet merupakan singkatan dari interconnected networking yang berarti jaringan komputer yang saling terhubung antara satu komputer dengan komputer yang lain yang membentuk sebuah jaringan komputer di seluruh dunia, sehingga dapat saling berinteraksi, berkomunikasi, saling bertukar informasi atau tukar menukar data (Nugraha, 2018). Disisi lain dampakdampak yang timbul akibat kurang mengetahuinya dampak positif dan negatif telah mendorong tim untuk melakukan pelatihan penggunaan internet sehat. Hal ini semata-mata adalah didorong oleh keprihatinan yang mendalam akan banyaknya penyalahgunaan internet untuk hal-hal yang tidak seharusnya dan sepantasnya. Melalui pelatihan penggunaan internet sehat ini, maka kami berkeinginan untuk ikut berperan serta dalam rangka meningkatkan pengembangan SDM bagi Pelajar SMP.

\section{METODE}

\section{Waktu dan Tempat}

Kegiatan pengabdian kepada masyarakat berupa Sosialisasi Penggunaan Internet Sehat Bagi Pelajar dilaksanakan pada 21 September 2019 bertempat di SMPN 5 Kawal Kecamatan Gunung Kijang, Kabupaten Bintan, Provinsi Kepulauan Riau.

\section{Prosedur Pelaksanaan dan Analisis Data}

Metode yang digunakan dalam pelaksanaan kegiatan Pengabdian Kepada
Masyarakat (PKM) berupa sosialisasi penggunaan internet sehat adalah dengan melakukan langkah-langkah sebagai berikut;

1) Sebelum melakukan pengabdian masyarakat terlebih dahulu melakukan pemetaan terhadap sekolah yang potensial sebagai tempat pelaksaan kegiatan.

2) Menjalin komunikasi dan diskusi dengan pimpinan instansi terkait yaitu Kepala Sekolah Menengah Pertama yang menjadi sasaran kegiatan pengabdian ini.

3) Melakukan survey lokasi yang akan dijadikan sebagai tempat untuk melakukan pengabdian masyarakat.

4) Menghubungi lokasi atau tempat untuk pelakasanaan kegiatan dan mendiskusikan topik yang hendak disosilisasikan.

5) Kegiatan pengabdian kepada masyarakat ini dilakukan dengan metode ceramah, kemudian diikuti dengan tanya jawab dengan peserta dilanjutkan dengan memberikan pelatihan bagaimana berinteraksi dengan internet yang sehat dan positif seperti dalam proses membuat facebook, tweeter, blog dan searching informasi sesuai dengan batasan yang dibutuhkan untuk pendidikan dan menambah wawasan seperti membuka media berita online agar terhindar dari hoaks.

6) Melakukan edukasi dan merancang kecerdasan,

7) Peningkatan knowledge, berupa pengetahuan yang disesuaikan dengan budaya, pendidikan masyarakat dimana lokasi kegiatan berada.

8) Mengadakan deklarasi "Penggunaan Internet Sehat Bagi Pelajar". 

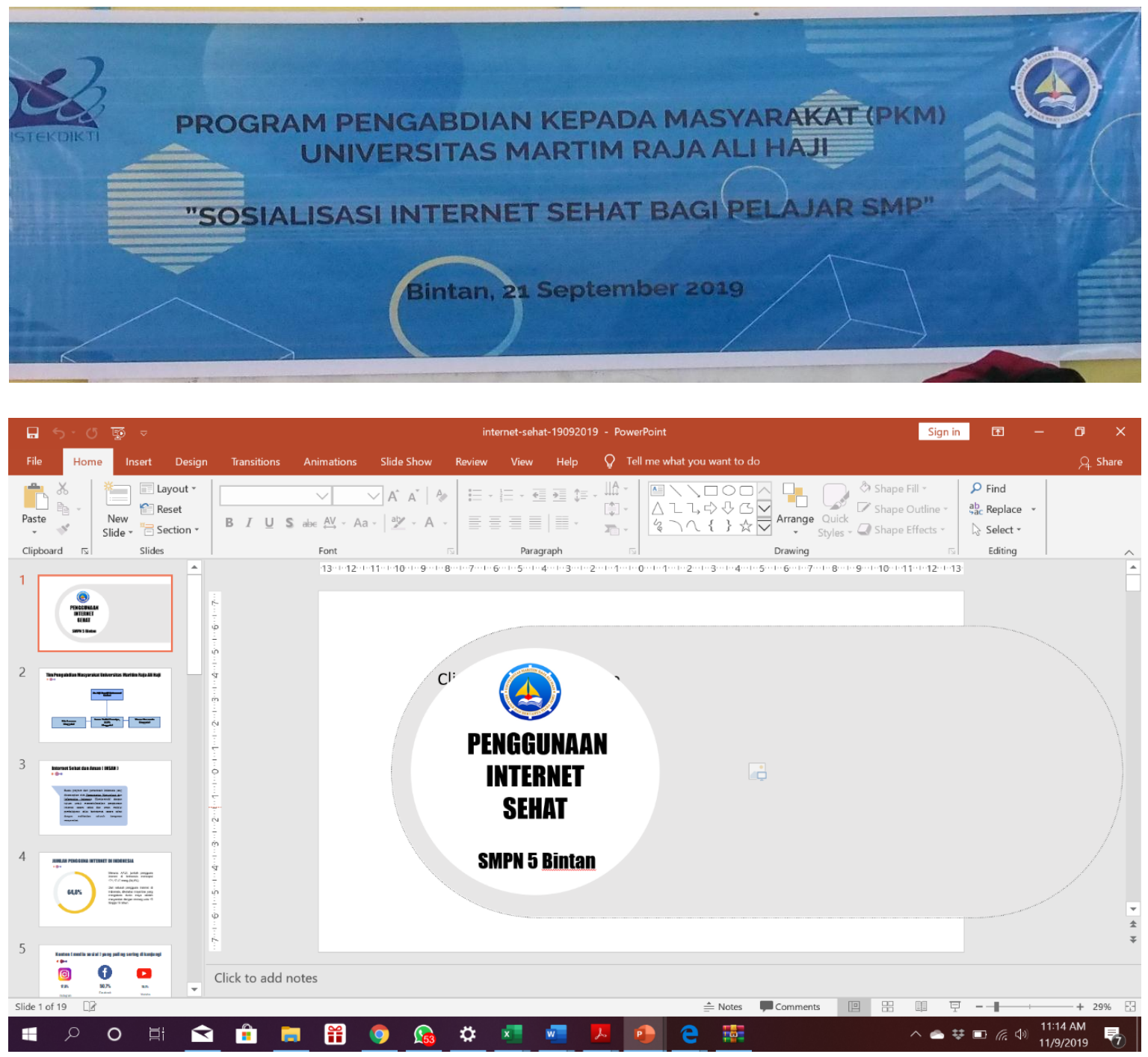

Gambar 1. Spanduk dan Materi Kegiatan Sosialisasi Internet Sehat Bagi Pelajar SMP

\section{HASIL DAN PEMBAHASAN}

\section{Tahapan Pelaksanaan Pengabdian}

Pada umumnya, dewasa ini pelajar memiliki akses yang mudah terhadap internet. Internet tidak lagi menjadi sesuatu yang mahal dan sulit. Bahkan internet saat ini sangatlah dengan mudah kita dapatkan. Beberapa lokasi strategis (publik) tidak jarang disediakan internet oleh pegelola baik pemerintah maupun swasta. Begitu mudahnya untuk mendapatkan akses internet ini sehingga ada adegium "tiada hari tanpa internet".

Pengabdian Kepada Masyarakat dengan tema "Sosialisasi Internet Sehat Bagi Pelajar di SMP N 5 Bintan" dilakukan sejak bulan Agustus 2019. Adapun kegiatan yang telah dilakukan adalah sebagai berikut;

1. Melakukan pemetaan untuk menentukan objek dan lokasi pengabdian kepada masyarakat.

2. Menjalin komunikasi dengan pihak SMPN 5 Bintan dalam hal ini kepala sekolah untuk menjajaki kemungkinan kerjasama dalam pelaksanaan pengabdian kepada masyarakat.

3. Melakukan kunjungan SMPN 5 Bintan untuk mematangkan rencana pelaksanaan pengabdian;
a) Maksud dan tujuan sosialisasi.
b) Konten yang disampaikan saat sosialisasi.
c) Waktu pelaksanaan.
d) Target peserta sosialisasi 
e) Luaran dari kegiatan sosialisasi.

4. Pelaksanaan sosialisasi dengan materi sebagai berikut:

a) Menjelaskan pengertian dan ruang lingkup internet.

b) Memberikan gambaran terkait konten media sosial yang sering dikunjungi.

c) Menjelaskan manfaat (pengembangan diri, bakat dan minat serta menunjang akademik) informasi dalam menyelesaikan tugas sekolah.
1) Media yang dapat membantu mencari
2) Mencari informasi baru atau yang sedang digemari.
3) Mencari teman baru
4) Wadah kreativitas dan inovasi.

d) Menjelaskan bahaya dari internet pagi pelajar.

1) Cyber bullying.

2) Cyber stalking.

3) Pelanggaran hak cipta.

4) Kasus-kasus kejahatan di internet.

e) Menginformasikan serta menjelaskan regulasi pemerintah berkaiatan dengan penggunaan teknologi informasi.

f) Menginformasikan cara pengaduan konten negatif.

g) Diskusi dan tanya jawab.

5. Deklarasi tentang penggunaan internet secara sehat dilingkungan SMPN 5 Bintan.

SMPN 5 Bintan dipilih sebagai lokasi pelaksanaan kegiatan PKM 2019 dengan tema "Sosialisasi Internet Sehat" mengingat bahwa sekolah ini menjadi sekolah model bagi SMP disekitar. Sebagai sekolah model maka sudah sepatutnya sekolah ini memiliki keunggulan dibandingkan dengan sekolah-sekolah sederajat lainya. Keteresidan tenaga pengajar atau guru yang membidangi Teknologi dan Informasi diharapkan mampu menjadi pelengkap dari output yang diinginkan dalam PKM ini.

Antusiasme pihak sekolah ditunjukkan dari kesiapanya dalam menyediakan berbagai keperluan untuk mendukung kegiatan mulai dari persiapan ruang, persiapan peserta dan persiapan-persiapan teknis lainya.

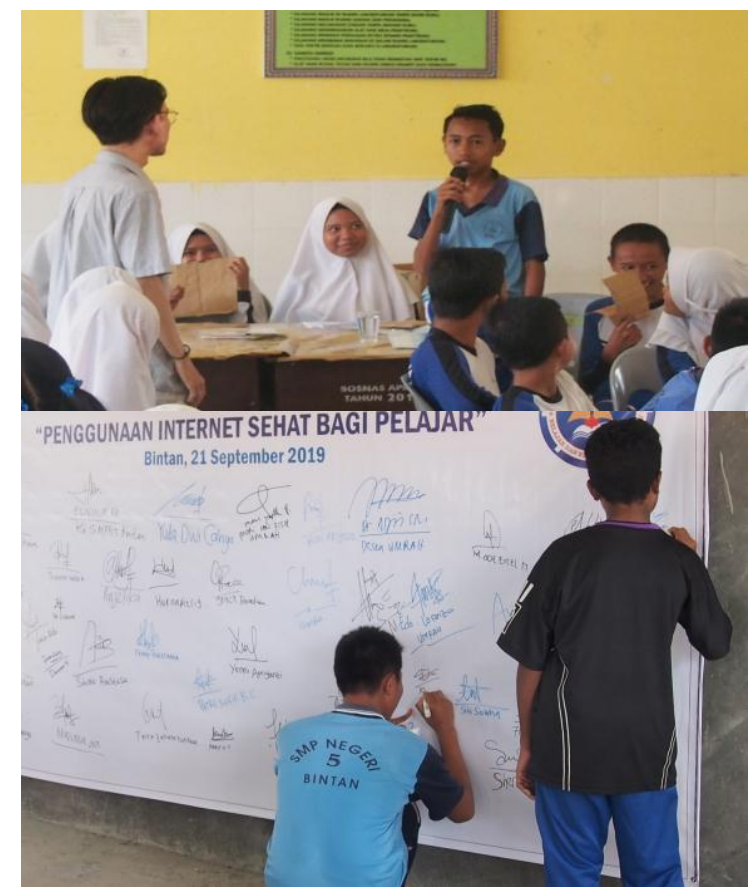

Gambar 2. Pemaparan Materi dan

Deklarasi Penggunaan Internet Sehat bagi Pelajar SMP

\section{Kondisi Existing Pelajar Bintan}

Teknologi informasi dan komunikasi atau yang lebih dikenal dengan sebutan TIK merupakan bagian dari Ilmu Pengetahuan dan Teknologi (IPTEK). Secara umum IPTEK adalah semua hal yang berkaitan erat dengan teknologi dan berhubungan dengan proses pengambilan, pengumpulan (akuisisi), pengolahan, penyimpanan, penyebaran, dan penyajian informasi. Perkembangan teknologi informasi merupakan konsekuensi dari perkembangan ilmu pengetahuan yang mendukung kebutuhan manusia saat ini. Pada kehidupan manusia modern, mereka membutuhkan kecepatan dan keefisienan dalam memenuhi kebutuhan hidupnya. Kehadiran teknologi informasi saat ini tidak bisa dihindari dan 
dibatasi penggunanya Hasil survei dari Asosiasi Penyelenggara Jaringan Internet Indonesia (APJII) pada tahun 2016 pengguna internet di Indonesia sebanyak 132,7 juta orang. Dimana total penduduk Indonesia 256,2 juta orang, artinya pengguna internet di Indonesia sebanyak 51,8\% (Wicaksono \& Rachmadyanti, 2016).

Dengan hadirnya teknologi informasi dan komunikasi, dalam hal ini popular dengan internet memberikan banyak manfaat bagi para penggunanya. Dampak positif dan negative dari penggunaan internet, adalah sebagai berikut(Rofadhilah, Taufik, \& Hakim, 2018)

Dampak positif dari TI antara lain:

a) Internet sebagai media komunikasi, merupakan fungsi internet yang paling banyak digunakan dimana setiap pengguna internet dapat berkomunikasi dengan pengguna lainnya dari seluruh dunia.

b) Media pertukaran data, dengan menggunakan email, newsgroup, ftp dan www (world wide web - jaringan situssitus web) para pengguna internet di seluruh dunia dapat saling bertukar informasi dengan cepat dan murah.

c) Media untuk mencari informasi atau data, perkembangan internet yang pesat, menjadikan www sebagai salah satu sumber informasi yang penting dan akurat.

d) Kemudahan memperoleh informasi yang ada di internet sehingga manusia tahu apa saja yang terjadi.

e) Bisa digunakan sebagai lahan informasi untuk bidang pendidikan, kebudayaan, dan lain - lain.

Selain pendapat diatas, pemanfaatan teknologi, khususnya komputer dan internet, memang memiliki banyak manfaat. Para siswa dapat memperoleh bahan-bahan pembelajaran melalui perpustakaan elektronik (elibrary) atau buku elektronik (e-book) untuk mendapatkan koleksi perpustakaan berupa buku, modul, jurnal, majalah atau surat kabar. Kehadiran internet juga memungkinkan dilakukannya pembelajaran jarak jauh (e-learning). Maksudnya untuk mendapatkan materi pelajaran, para siswa atau mahasiswa tidak harus terikat dengan ruang dan waktu di ruang kelas pada jamjam pelajaran. Materi bisa didapat melalui komputer di rumah yang tersambung dengan internet atau melalui warnet-warnet yang memberikan layanan akses internet. Bahkan, dimungkinkan para siswa atau mahasiswa melakukan komunikasi dengan guru atau dosen melalui fasilitas e-mail atau berbicara atau bertatap muka melalui fasilitas teleconference (videoconference)(Maryono dan Istiana, 2007)

Perlu disadari bahwa, selain internet memiliki banyak manfaat juga ada beberapa hal yang dapat atau perlu diwaspadai dalam penggunaan internet. Dampak negatif dari TI diantaranya (Rofadhilah et al., 2018):

a) Pornografi. Anggapan yang mengatakan bahwa internet identik dengan pornografi, memang tidak salah. Dengan kemampuan penyampaian informasi yang dimiliki internet, pornografi pun merajalela.Untuk mengantisipasi hal ini, para produsen 'browser' melengkapi program mereka dengan kemampuan untuk memilih jenis home-page yang dapat di-akses. Di internet terdapat gambar - gambar pornografi dan kekerasan yang bisa mengakibatkan dorongan kepada seseorang untuk bertindak kriminal.

b) Violence and Gore. Kekejaman dan kesadisan juga banyak ditampilkan. Karena segi bisnis dan isi pada dunia internet tidak terbatas, maka para pemilik situs menggunakan segala macam cara agar dapat 'menjual' situs mereka. Salah satunya dengan menampilkan hal-hal yang bersifat tabu.

c) Penipuan. Hal ini memang merajalela di bidang manapun. Internet pun tidak luput dari serangan penipu. Cara yang terbaik adalah tidak mengindahkan hal ini atau mengkonfirmasi informasi 
yang Anda dapatkan pada penyedia informasi tersebut.

d) Carding. Karena sifatnya yang 'real time' (langsung), cara belanja dengan menggunakan Kartu kredit adalah cara yang paling banyak digunakan dalam dunia internet. Para penjahat internet pun paling banyak melakukan kejahatan dalam bidang ini. Dengan sifat yang terbuka, para penjahat mampu mendeteksi adanya transaksi (yang menggunakan Kartu Kredit) on-line dan mencatat kode Kartu yang digunakan. Untuk selanjutnya mereka menggunakan data yang mereka dapatkan untuk kepentingan kejahatan mereka.

e) Perjudian. Dampak lainnya adalah meluasnya perjudian. Dengan jaringan yang tersedia, para penjudi tidak perlu pergi ke tempat khusus untuk memenuhi keinginannya. Anda hanya perlu menghindari situs seperti ini, karena umumnya situs perjudian tidak agresif dan memerlukan banyak persetujuan dari pengunjungnya.

Selain itu Teknologi Informasi juga berdampak negatif dalam ranah hubungan social. Diantara dampak negative dari penggunaan Teknologi Informasi tersebut antara lain;

a) Mengurangi sifat sosial manusia karena cenderung lebih suka berhubungan lewat internet daripada bertemu secara langsung (face to face).

b) Dari sifat sosial yang berubah dapat mengakibatkan perubahan pola masyarakat dalam berinteraksi.

c) Kejahatan seperti menipu dan mencuri dapat dilakukan di internet (kejahatan juga ikut berkembang).

d) Bisa membuat seseorang kecanduan, terutama yang menyangkut pornografi dan dapat menghabiskan uang karena hanya untuk melayani kecanduan tersebut.

\section{Beragamnya Permasalahan Penggunaan Internet.}

Permasalah lain yang kemudian timbul dari mudahnya mengakses internet, dan setiap kalangan masyarakat baik masyarakat perkotaan- pedesaan, setiap jenjang umur dan hampir setiap pekerjaan adalah penggunaan internet yang belebihan. Pada umumnya kencanduan ini lebih pada internet yang dipergunakan untuk hiburan.

Menurut Young dalam (Dewi \& Trikusumaadi, 2017) aspek-aspek kecanduan internet meliputi beberapa hal berikut ini:

a) perhatian tertuju pada aktivitas online;

b) ingin bermain internet dalam jumlah waktu yang semakin meningkat untuk mendapatkan kepuasan;

c) tidak dapat mengontrol, mengurangi atau menghentikan kegiatan berinternet;

d) merasa gelisah, tertekan, lekas marah ketika mengurangi atau menghentikan penggu-naan internet;

e) online lebih lama dari waktu yang direncanakan;

f) menjadikan internet sebagai cara untuk melepaskan diri dari berbagai permasalahan atau melepaskan diri dari perasaan yang tidak menyenangkan;

g) selalu kembali menggunakan internet walaupun sudah banyak menghabiskan; kecenderungan untuk menarik diri ketika offline;

h) berani mengambil resiko kehi-langan hubungan dengan orang terdekat, pekerjaan, pendidikan, atau karir karena bermain internet;

i) berbohong terhadap anggota keluarga untuk mengurangi tingkat hubungan bermain internet.

Selain itu, seseorang bisa menderita adiksi kepada komputer dan mengalami gejala-gejala withdrawl bila menghentikan kegiatan tersebut. Bentuk lain adiksi ini meliputi adiksi internet dan video game. Akibat adiksi ini akan menimbulkan 
masalah akademis dan fungsi hubungan sosial lainnya. Pola kecanduan internet nampak mirip dengan gejala kecanduan pada zat psikoaktif, dengan demikian, dapat dikatakan bahwa kecanduan internet merupakan pola kecanduan yang sudah dikenal sejak lama dengan objek yang lebih modern (Dewi, 2011).

Dengan melihat ekses dari penggunaan internet khusus bagi anak usia sekolah yang cukup tinggi, maka penting kiranya memberikan pembekalan bagi mereka bagaimana menyikapi dan menggunakan internet secara sehat. Khusus untuk SMPN 5 Bintan merujuk informasi dan keterangan dari Kepala Sekolah, belum ada atau belum pernah dilakukan sosialisasi ata pelatihan penggunaan internet secara sehat. Dengan demikin maka kegiatan sosialisasi internet sehat ini sangat diperlukan dan sangat bermanfaat.

\section{KESIMPULAN}

Kegiatan pengabdian kepada masyarakat yang dilakukan oleh Tim Universitas Maritim Raja Ali Haji melalui sosialisasi internet sehar pada pelajar di SMPN 5 Bintan telah terlaksana dengan baik. Kerjasama yang baik antara UMRAH dan sekolah telah terbangun serta penerimaan positif dari pihak sekolah khususnya SMPN 5 Bintan diharapkan dapat memberikan manfaat bagi siswa maupun sekolah dalam memanfaatkan media internet dalam pengembangan diri maupun sekolah secara organisasi.

Keberadaan Internet dan media social tidak mungkin kita hindari mengingat bahwa pada prinsipnya manusia selalu ingin memenuhi kebutuhannya. Internet dan media social harusnya tidak lagi menjadi momok yang selalu dipandang negative. Agar tidak menjadi momok yang bernilai negative, maka perlu upaya untuk memanfaatkan internet dan media social dengan baik. Internet dan media social harus dimanfaatkan secara bijak sehingga dapat memberikan "nilai lebih" khususnya dalam hal pengembangan diri yang kemudian akan mampu menunjang prestrasi akademik maupun minat dan bakat para siswa.

Pengabdian yang telah dilaksanakan baru berupa sosialisasi internet sehat, akan tetapi kedepannya kami akan terus melakukan komunikasi dengan pihak sekolah berkaitan dengan pemanfaatan secara teknik berkaitan teknologi informasi lebih lanjut sehingga dapat menunjang prestasi siswa. Tidak menutup kemungkinan program selanjutnya merupakan program yang sifatnya berdasarkan permintaan pihak sekolah sesuai dengan kebutuhan mereka.

\section{UCAPAN TERIMAKASIH}

Terimakasih kami ucapkan kepada Universitas Maritim Raja Ali Haji melalui Lembaga Penelitian, Penjaminan Mutu dan Pengabdian Kepada Masyarakat yang telah memfasilitasi Pengabdian Kepada Masyarakat khususnya dalam hal sosialisasi penggunaan internet sehat. Tak lupa kami juga mengucapkan terimakasih dan penghargaan yang setinggi-tingginya kepada Kepala Sekolah SMPN 5 Bintan yang telah bersedia bekerjasama dalam memperlancar kegiatan ini dan semoga kedepan kita bisa saling melengkapi.

\section{DAFTAR PUSTAKA}

Anggreini, N. M., Nasir, B. M. S., \& Noor, I. L. S. S. M. (2016). Pemanfaatan Media Sosial Twitter di Kalangan Pelajar SMK Negeri 5 Samarinda. Sosiologi, 4(2), 239-251. Retrieved from https://ejournal.sos.fisipunmul.ac.id/site/wpcontent/uploads/2016/06/02_format_a rtikel_ejournal_mulai_hlm_genap-1 (06-16-16-07-26-19).pdf

Asniati.et.all. (2020). Pengaruh Penggunaan Internet Terhadap Kenakalan Remaja (Siswa). Jurnal Bening, 4, 17-26. Retrieved from http://ojs.uho.ac.id/index.php/bening/ article/view/10485/7354

Dewi, N. (2011). Hubungan Antara 
Kecanduan Internet dan Kecemasan Dengan Insomnia Pada Mahasiswa S1 FK UNS Yang Sedang Skripsi. Surakarta: UNS Press.

Dewi, N., \& Trikusumaadi, S. K. (2017). Bahaya Kecanduan Internet dan Kecemasan Komunikasi terhadap Karakter Kerja Sama pada Mahasiswa. Jurnal Psikologi, 43(3), 220. https://doi.org/10.22146/jpsi.16829

Hidayanto, F., \& Zidni Ilmi, M. (2015). Pentingnya internet sehat. Jurnal Inovasi Dan Kewirausahaan, 4(1), 2124.

Maryono dan Istiana. (2007). Pemanfaatan Internet Dan Dampaknya Pada Pelajar Sekolah Menengah Atas Di Surabaya. Libri-Net, 3(1), 407-412. Retrieved from

http://journal.unair.ac.id/filerPDF/ln5 ba2011865full.pdf

Nugraha, A. (2018). Edukasi Internet Sehat dan Aman. Pelita Ilmu, 1(1), 22-32.
Retrieved

from http://jurnal.stiapembangunanjember. ac.id/index.php/pelitailmu/article/vie w/94/120

Rofadhilah, Taufik, O. A., \& Hakim, L. (2018). Dampak Penggunaan Teknologi Internet Terhadap Di Jakarta Utara. Jisamar, 2(1), 25-46.

Rosyidah, R. (2016). Pengaruh Media Sosial Terhadap Penyimpangan Perilaku Pada Siswa. Millah, XIV(2), 47-66.

https://doi.org/10.20885/millah.volxiv .iss $2 . \operatorname{art} 3$

Wicaksono, V. D., \& Rachmadyanti, P. (2016). Pembelajaran Blended Learning melalui Google Classroom di Sekolah Dasar. Seminar Nasional Pendidikan PGSD UMS \& HDPGSDI Wilayah Timur, 513-521. Retrieved from http://hdl.handle.net/11617/9144

Diterima : 16 April 2020

Disetujui : 15 Mei 2020 